Research Article

\title{
Mining-Induced Pressure-Relief Mechanism of Coal-Rock Mass for Different Protective Layer Mining Modes
}

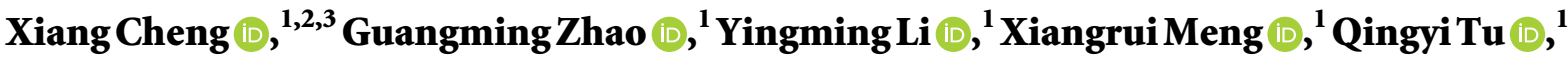 \\ Shunjie Huang $\mathbb{D}^{1}{ }^{1}$ and Zhihong Qin $\mathbb{D}^{1}$ \\ ${ }^{1}$ State Key Laboratory of Mining Response and Disaster Prevention and Control in Deep Coal Mines, \\ Anhui University of Science and Technology, Huainan 232001, China \\ ${ }^{2}$ Geological Resources and Geological Engineering Post-Doctoral Flow Station, Anhui University of Science and Technology, \\ Huainan 232001, China \\ ${ }^{3}$ Post-Doctoral Research Station, Huaibei Mining Corporation Limited, Huaibei 235006, China
}

Correspondence should be addressed to Xiang Cheng; cxaust@163.com

Received 14 April 2021; Accepted 15 June 2021; Published 12 July 2021

Academic Editor: Akbar Heidarzadeh

Copyright (C) 2021 Xiang Cheng et al. This is an open access article distributed under the Creative Commons Attribution License, which permits unrestricted use, distribution, and reproduction in any medium, provided the original work is properly cited.

\begin{abstract}
The protective layer mining method of the traditional deep coal seam in has been confronted with great challenges, and it is difficult for coal and gas to be extracted together. Taking the occurrence conditions of III1 mining area of Luling Coal Mine located at Huaibei, China, as engineering background, the influence law of the lithology on stress environment in front of the stope was analyzed by theoretical analysis and numerical simulations. The mining-induced mechanical effect of coal-rock mass was studied under different protective layer mining modes. The results showed that the peak value of the advanced abutment pressure decreased with the decrease of lithologic strength under the same mining conditions. For simulated geological conditions, the stress concentration coefficient of soft rock and coal seam protective layer mining modes was 1.9 and 1.7, respectively. Under the mining stress path of different protective layers, the ratio of axial stress increase and confining pressure unloading in secondary unloading phase were $2: 1$ and $1.5: 1$, respectively. The axial stress-strain curves of different protective layer mining modes had similar trends, and they had a volume expansion at the end of unloading (failure stage). In addition, it revealed the pressure-relief antireflection mechanism of the protective layer mining. Under the same confining pressure condition, the peak stress and peak strain increased with the increase of loading and unloading velocity ratio. The reduced value of the confining pressure increased, while the volume expansion decreased at failure. The results were applied to III1 mining area in soft rock protective layer mining, which created the mining way of traditional coal seam protective layer. Furthermore, the gas control technology of soft rock protective layer working face was put forward for deep coal seam with low permeability and high gas, enriching the pressure-relief mining theory of protective layer.
\end{abstract}

\section{Introduction}

In China, the deep resource exploitation has been one of the development strategies [1]. The geological conditions of coal resources are complicated, and the ground stress increases after entering the deep mine. Meanwhile, the gas pressure and gas content in coal seam also increase. All the factors interact and influence each other, and the gas disaster becomes more and more serious [2-4]. The traditional protective layer mining method of the coal seam encounters great challenges. There is no suitable technical condition for coal seam to be mined as the protective layer, which increases the difficulty of coal and gas mining. It seriously restricts the development of coal mines under the new situation in China. Therefore, it is urgent to seek an innovative and safe mining method of the protective layer, to realize the disaster prevention of deep coal seams (or groups) with low permeability and high gas. Because of the flexible layer selectivity, adjustable mining thickness, no gas in mining layer, small threat to mining safety, and so on, the soft rock protective layer mining is used to achieve efficient gas control. It has 
a wide application prospect in the selection of the first mining pressure-relief layer for the gas coal seams with low permeability in deep.

The longwall mining method has been widely used in underground coal mines in many countries such as America and China. In the longwall mining practice of single coal seam, the stress field in surrounding rock of the stope is redistributed due to the working face mining [5], which is manifested as the stress release in excavation direction and concentration in vertical excavation direction [6-8]. Based on various geological conditions, different mining layouts have been used in mining practices to achieve safe and efficient excavation. Xie et al. [9] proposed the concept of mining-induced mechanical behavior and analyzed mininginduced mechanical characteristics of coal mass in front of the stope under three typical mining layouts, i.e., top-coal caving, nonpillar mining, and coal seam mining. Taking the coal of Tashan Mine in Datong as the research object, Zhang et al. [10] simulated the mining-induced failure experiments by three typical mining layouts. For No. 4 coal seam of Baijiao Mine in Yibin, Zhang et al. [3] analyzed the effect of mining layouts on mechanical behavior of coal using a MTS815 rock mechanics testing system. Zuo et al. [11] studied the effect of stress path on mechanical behavior of the surrounding rock under different mining unloading conditions of the limestone in Licun Coal Mine. Under different stress paths, Wang et al. [12] studied the mechanical behaviors for three types of rocks (coal, mudstone, and sandstone) by uniaxial compression. Similar, Wang et al. [13] studied mechanical parameters and AE response characteristics of anthracitic coal samples in uniaxial compression experiments. Yin et al. [14] analyzed the damage and repair mechanical characteristics of rock salts. In the conventional triaxial compression tests with five confining pressures, Peng et al. [15] studied the relation between energy transformation and coal failure for coal samples in $600 \mathrm{~m}$ deep mine. In order to obtain the loss evolution law of coal-rock mass at different depths under triaxial compression, Jia et al. [16] carried out mechanical behaviors and real-time acoustic emission tests, clarifying the difference between deep rock and shallow rock. Zhang et al. [17] used a servo-controlled rock mechanics testing system to study three sandstone samples with different compositions. The macroscopic failure characteristics and complete stress-strain curves were obtained in triaxial compression tests. Yang et al. [18] studied the fractal characteristics of limestone fragments obtained in conventional compression and cyclic loading tests under uniaxial/triaxial conditions. Li et al. [19] analyzed the deformation, strength, and acoustic emission characteristics of sandstone by true triaxial compression tests. Xue et al. [20] studied mechanical behaviors of gas-containing coal samples under constant/unloading confining pressure paths. Li et al. [21] carried out unloading confining pressure tests of granite samples at different unloading rates, to analyze the relation between unloading rate and mechanical properties of rocks. In triaxial experiments, Zhao et al. [22] subjected sandstone to different initial confining pressures and unloading rates under fixed axial stress. The mechanical response, deformation behavior, and permeability evolution of surrounding rocks were analyzed in detail.

Most previous studies have focused on coal seam as protective layer mining, top-coal caving, and nonpillar mining. Meanwhile, the uniaxial, triaxial, and unloading confining pressures are mainly studied for stress path. The real influence of mining modes and engineering disturbance cannot be reflected, and it is rarely reported mining practice of soft rock protective layer as working face. To the best of our knowledge, no study has investigated the mining-induced mechanical effect of coal-rock mass in front of stope for soft rock protective layer mining. Due to different mining modes (or stratum lithology) of the protective layer, there is significantly different stress environment in front of stope. Furthermore, it shows different distribution characteristics of abutment pressure, corresponding to different loading and unloading stress paths. The mininginduced mechanical response is different for coal-rock mass. Therefore, the exploration of mining-induced pressure-relief mechanical effect under soft rock protective layer mining mode will enrich the pressure-relief mining theory of protective layer, and it has a positive significance to improve the acquisition ability of deep resources.

Based on the above analysis, the pressure-relief and permeability enhancement of the protective layer mining was explored under the specific mining geological conditions. The influence of lithology on stress environment in front of stope was studied. The mining-induced mechanical effect was analyzed for different protective layer mining modes, and the soft rock protective layer mining was put forward for on-site engineering application, which provided an important theory support for coal and gas mining by different protective layer mining modes.

\section{Effect of Stratum Lithology on Stress Environment in front of Stope}

2.1. Theoretical Analysis of Stress Environment for Coal-Rock Mass. Figure 1 shows a zoning mechanical model of abutment pressure based on the limit equilibrium theory. The coal (or rock) mass in front of the stope is divided into limit equilibrium zone and elastic zone [23]. In the limit equilibrium zone, the following equation can be obtained by Mohr-Coulomb strength criterion according to the condition that the stress of coal (or rock) mass satisfies

$$
\sigma_{y}=R_{c}+\frac{1+\sin \varphi}{1-\sin \varphi} \sigma_{x}
$$

where $\sigma_{y}$ is the pressure on the unit in the $y$ direction, $\mathrm{MPa}$; $R_{c}$ is the uniaxial compressive strength, $\mathrm{MPa} ; \varphi$ is the internal friction angle, ${ }^{\circ}$; and $\sigma_{x}$ is the pressure on the coal (or rock) wall side of unit in the $x$ direction, MPa.

After simplification, equation (1) can be obtained as follows:

$$
\sigma_{y}=\tau_{0} \cot \varphi\left(\frac{1+\sin \varphi}{1-\sin \varphi}\right) e^{((2 f x / m)(1+\sin \varphi / 1-\sin \varphi))},
$$

where $\tau_{0} \cot \varphi$ is the self-supporting force of coal (or rock) mass, $\mathrm{MPa}$; $f$ is the interlayer friction coefficient; $m$ is the 


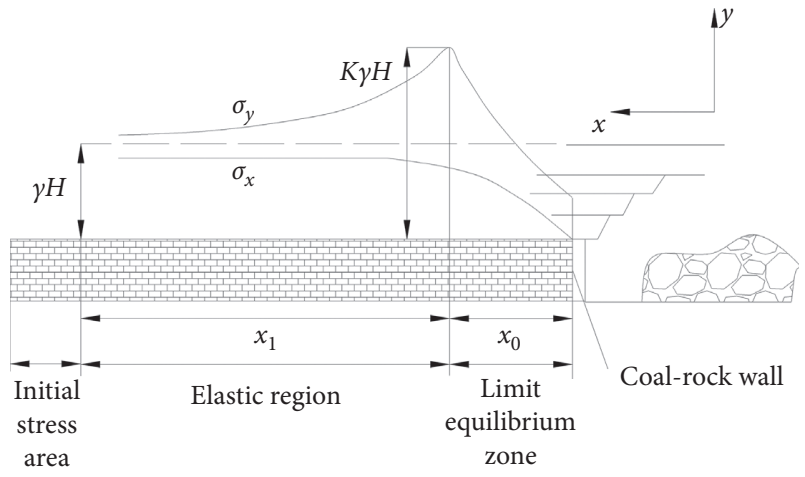

FIgURE 1: Area partition of abutment pressure.

mining height, $\mathrm{m}$; and $x$ is the distance from coal (or rock) mass at any point in the limit equilibrium area, $\mathrm{m}$.

Combined with the peak abutment pressure: $\sigma_{y \text { max }}=K \gamma H$, the distance between the peak value of abutment pressure and coal (or rock) wall is obtained by the following equation:

$$
x_{0}=\frac{m}{2 f} \frac{1+\sin \varphi}{1-\sin \varphi} \ln \left(\frac{K \gamma H}{\tau_{0} \cot \varphi} \cdot \frac{1+\sin \varphi}{1-\sin \varphi}\right),
$$

where $K$ is the stress concentration factor; $\gamma$ is the bulk density of coal (or rock) mass, $\mathrm{N} / \mathrm{m}^{3}$; and $H$ is the mining depth, $m$.

When the buried depth of working face and structure of overlying strata are the same, the working face with different stratum lithology, the peak value of the advanced abetment pressure becomes smaller with the decrease of stratum lithology strength. It is found that the ore body of soft rock protective layer mining is different from that of the traditional coal seam protective layer mining under the same conditions. The different stress environment in front of stope can lead to different mining-induced effects.

2.2. Numerical Analysis of Stress Environment for Coal-Rock Mass. Apart from the traditional coal seam as protective layer, other mining modes in engineering practice are extremely rare. It is difficult to detect all stress environments of rock working faces with different stratum lithology features by on-site monitoring. Most noteworthy, the stress environment of working faces can be simulated by giving different mechanical parameters of coal strata for the numerical simulation. Based on FLAC ${ }^{3 D}$ numerical simulation software and Mohr-Coulomb constitutive model, the initial values of physical properties of coal-rock mass are simulated for the occurrence conditions of III1 mining area in Luling Coal Mine. The mechanical model is shown in Figure 2. Different stratum lithology features are simulated by adjusting mechanics parameters of the exploited horizon. Three stratum lithology features are designed, including coal, mudstone, and sandstone. The mechanical parameters are listed in Table 1, and the physical and mechanical parameters of other rock strata can be referred to the reported paper [24].
When the working faces of protective layer with different lithologies are mined, the peak value of abutment pressure in front of working face changes with the stratum lithology, which leads to the difference of stress environment in front of stope. Figure 3 shows the abutment pressure distribution curve in front of stope for protective layer working face with different stratum lithology features. It is found that the peak value of abutment pressure increases with the increase of lithology strength. When coal, mudstone, and sandstone are mined, the maximum vertical stress of surrounding rocks is 29.5, 31.5, and 35.0 MPa, respectively. The corresponding maximum stress concentration coefficient is $1.74,1.86$, and 2.07 , respectively. The reason for the difference is that, due to different mechanical parameters of the mining layers, the "coal (or rock) wall-fallen rock refuse" support system formed after mining working face has different abilities to support the formation structure of overburden, resulting in the various stress environments in front of stope. Therefore, the disturbance of coal-rock mass in front of working face is different for different protective layer mining modes.

2.3. Stress Environment of Coal-Rock Mass for Different Protective Layer Mining Modes. According to the above numerical calculation results, the stress concentration coefficient of soft rock protective layer mining is 1.9, while that of coal seam protective layer mining is 1.7 under simulated geological conditions. It indicates that the axial stress increases under different protective layer mining modes. Figure 4 shows the stress environment of coal-rock mass in front of working face. It is assumed that the coal-rock masses in the working face are all in a hydrostatic pressure state before the mining of the protective layer working face, which can be described as $\sigma_{1}=\sigma_{3}=\gamma H$. The stress concentration coefficient caused by different protective layer mining modes is $\alpha$. When the vertical stress of $\sigma_{1}$ rises to peak stress, the horizontal stress of $\sigma_{3}$ corresponds to the unloading state at point two and point three in Figure 4 [25].

The formula is as follows:

$$
\left\{\begin{array}{l}
\text { Point two: } \sigma_{3}=\frac{2}{5} \sigma_{1}, \\
\text { point three }: \sigma_{3}=\frac{1}{5 \alpha} \sigma_{1} .
\end{array}\right.
$$

The mining stress environment of coal-rock mass in front of protective layer takes into account the influence of protective layer mining depth and mining modes on its mechanical properties. Different protective layer mining modes lead to different unloading stress paths, so that the mechanical behavior of coal-rock mass is also different.

\section{Mining-Induced Mechanics Experiments of Coal-Rock Mass under Different Protective Layer Mining Modes}

3.1. Determination of Stress Paths. For different protective layer mining modes, the stress environment change in front of stope is reflected in different velocity ratios of loading and 


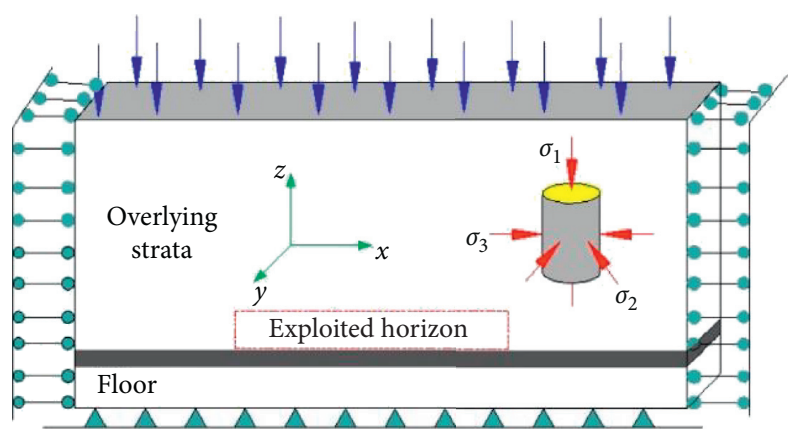

Figure 2: Mechanical model diagram of numerical calculation.

TABLE 1: Mechanical parameters of mining seam.

\begin{tabular}{lccccc}
\hline Coal-rock & Density $\left(\mathrm{kg} / \mathrm{m}^{3}\right)$ & Elastic modulus $(\mathrm{GPa})$ & Deformation modulus $(\mathrm{GPa})$ & Poisson's ratio & Tensile strength $(\mathrm{MPa})$ \\
\hline Coal & 1380 & 2.08 & 1.62 & 0.18 & 0.9 \\
Mudstone & 2410 & 4.791 & 4.193 & 0.233 & 2.4 \\
Sandstone & 2700 & 10.25 & 9.419 & 0.315 & 4.2 \\
\hline
\end{tabular}

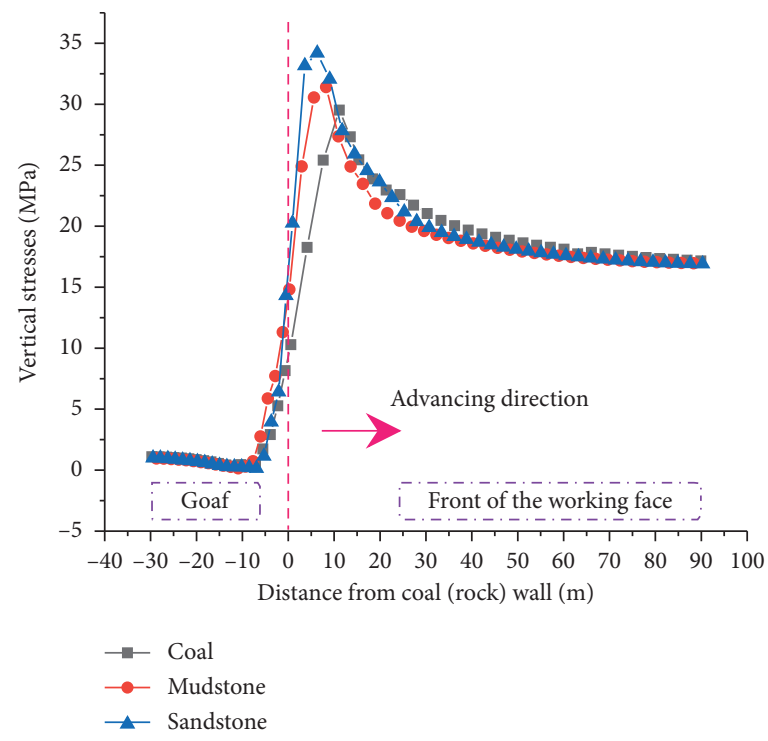

FIGURE 3: Distribution curves of preabutment pressure in front of stope with different stratum lithology features.

unloading. In order to simulate mining-induced mechanics behaviors in the protective layer mining modes, the axial compressive force and variation of confining pressure were adopted to simulate the abutment pressure and horizontal stress, respectively. The variation characteristics of horizontal stress unloading and vertical stress rise in front of stope in the protective layer were simulated by increasing axial stress and reducing confining pressure. According to formula (4), the ratio of axial stress to confining pressure was designed at a fixed position. The whole loading and unloading process can be divided into three stages, hydrostatic pressure loading stage, primary unloading stage, and secondary unloading stage, as shown in Figure 5.

(1) Hydrostatic pressure loading stage (OA section): the ratio of axial pressure to confining pressure is 1 for simulating hydrostatic pressure characteristics of coal-rock mass unaffected by mining. (2) Primary unloading stage (AB section): the axial pressure is increased, and confining pressure is reduced in the loading mode with the ratio of the axial stress increase and confining pressure decrease greater than 1 . The axial stress is increased to $1.5 \gamma H$, the horizontal stress is unloaded to $0.6 \gamma \mathrm{H}$, and the ratio between axial stress increase $\left(\sigma_{1}-\sigma_{3}\right)$ and confining pressure unloading $\left(\sigma_{3}\right)$ is $2.25: 1$. (3) Secondary unloading stage (BC/BD section): the concentration coefficient in the soft rock protective layer mining mode increases from 1.5 to 1.9 in peak stress state, and the horizontal stress is unloaded to $0.2 \gamma \mathrm{H}$. The ratio between $\left(\sigma_{1}-\sigma_{3}\right)$ and $\sigma_{3}$ is $2: 1$, as shown in BC section. Under the coal seam protective layer mining mode, the ratio between $\left(\sigma_{1}-\sigma_{3}\right)$ and $\sigma_{3}$ is $1.5: 1$, as shown in BD section.

3.2. Experimental Equipment and Scheme. A true triaxial testing system with disturbance unloading rock was used as shown in Figure 6. Samples were taken from surrounding 


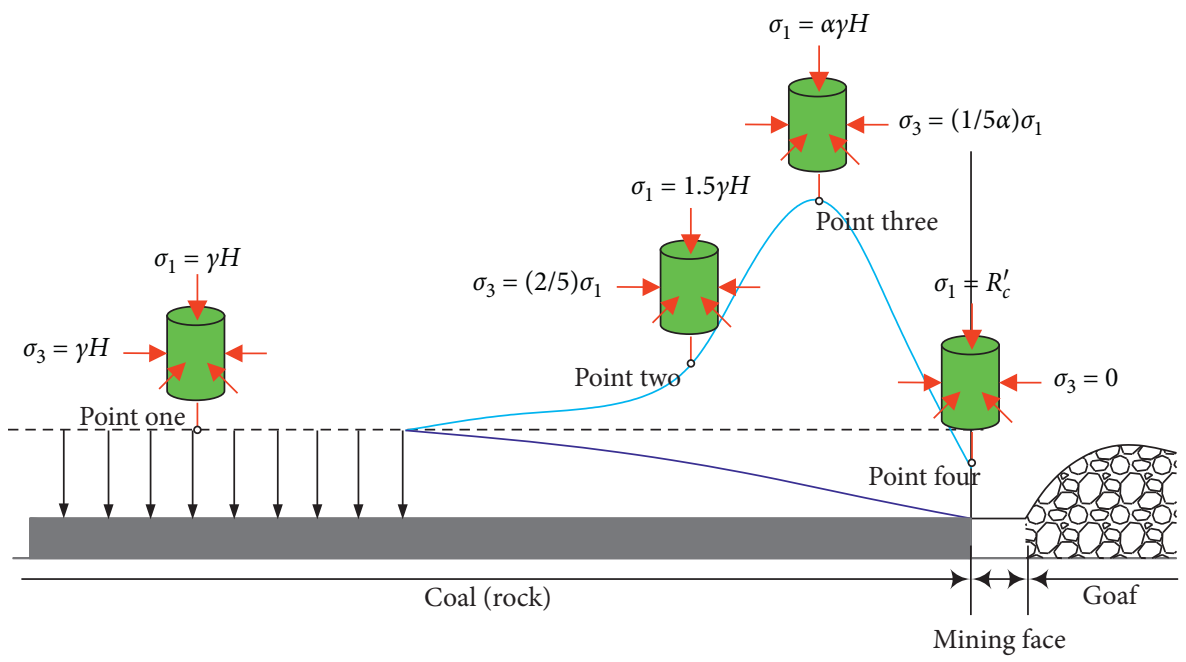

FIGURE 4: Stress environment in front of stope in the mining face under different protective layer mining modes.

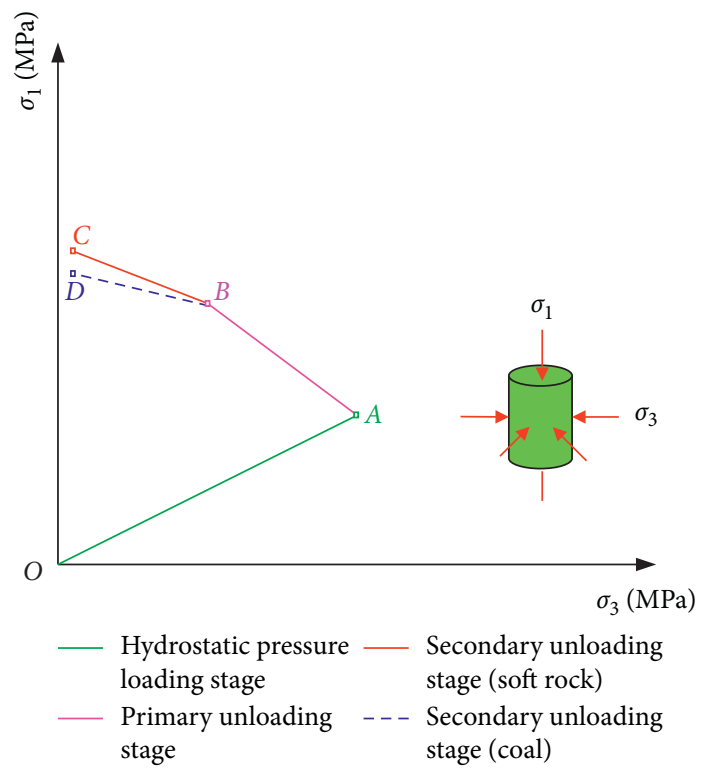

FIGURE 5: Mining-induced mechanics stress path.

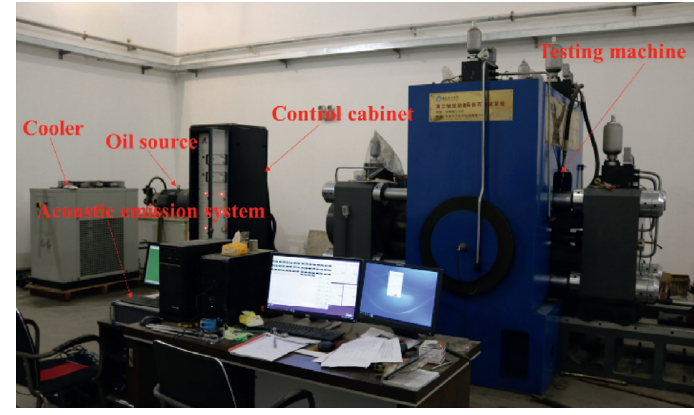

Figure 6: True triaxial disturbance unloading rock test system.

rocks in stope of III11 soft rock working face in Luling Coal Mine. Figure 7 displays some processed rock samples (cube specimens: $10 \mathrm{~cm} \times 10 \mathrm{~cm} \times 10 \mathrm{~cm}$ ).
Different initial confining pressures were applied to rock samples at different mining depths, which were $15 \mathrm{MPa}$ (about $600 \mathrm{~m}$ hydrostatic pressure), $20 \mathrm{MPa}$ (about $800 \mathrm{~m}$ hydrostatic pressure), and $25 \mathrm{MPa}$ (about $1000 \mathrm{~m}$ hydrostatic pressure), respectively. The test results of conventional triaxial loading show that the peak strength of rock samples was $113 \mathrm{MPa}\left(\sigma_{2}=\sigma_{3}=20 \mathrm{MPa}\right)$ as shown in Figure 8 . According to the treatment method in reported paper [11], when the initial confining pressure was $15 \mathrm{MPa}$, the peak strength of surrounding rock was assumed to be about $130 \mathrm{MPa}$; it was 8.67 times that of hydrostatic pressure. For the soft rock protective layer mining, the ratio of axial loading rate to lateral unloading rate was 2 . When the initial confining pressure was $15 \mathrm{MPa}, 20 \mathrm{MPa}$, and $25 \mathrm{MPa}$, $\Delta \sigma_{1} / \Delta \sigma_{3}$ were designed to be $9.13: 1,6.84: 1$ and $5.47: 1$ of the surrounding rock, respectively. For the coal seam protective layer mining, the ratio of axial loading rate to lateral 


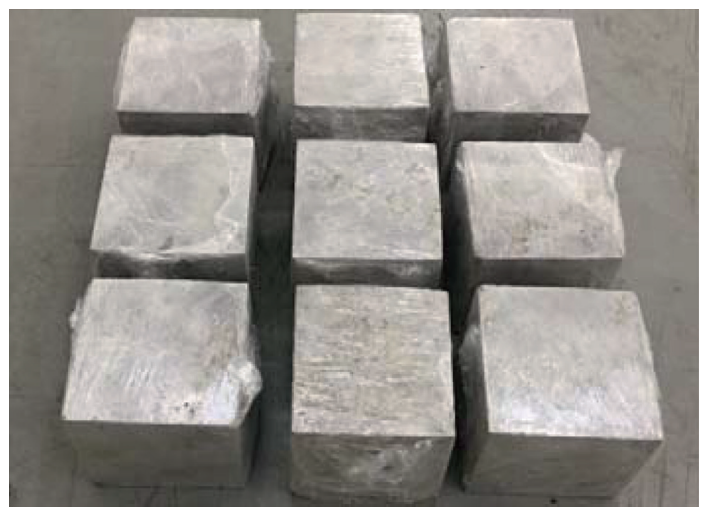

Figure 7: Partial processed sandstone specimens.

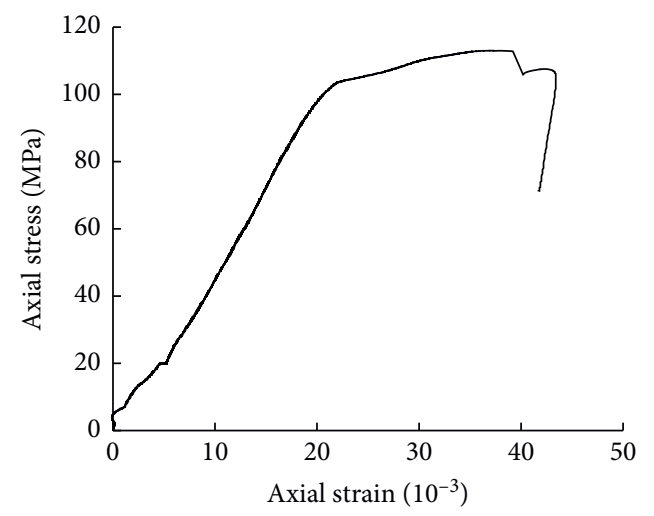

Figure 8: Axial stress-strain curves of sandstone under conventional triaxial loading at $20 \mathrm{MPa}$ confining pressure.

unloading rate was 1.5 . When the initial confining pressure was $15 \mathrm{MPa}$ and $25 \mathrm{MPa}, \Delta \sigma_{1} / \Delta \sigma_{3}$ were designed to be 7.65 : 1 and $4.59: 1$. In the experiment, the designed unloading rate was $0.5 \mathrm{MPa} / \mathrm{min}$, and the displacement control was adopted after the peak. Meanwhile, the confining pressure unloading rate remained unchanged. The specific experimental scheme is listed in Table 2.

\subsection{Experimental Steps}

(1) Hydrostatic pressure loading stage: using a force control method, the loading was carried out at a speed of $35 \mathrm{kN} / \mathrm{min}$ in vertical direction and $30 \mathrm{kN} /$ min in horizontal direction, respectively, to the hydrostatic pressure stage, and the loading speed was about $1: 1$.

(2) Primary unloading stage: this was the initial stage of simulated mining-induced effects. From the hydrostatic pressure level, the ratio of axial loading rate to lateral unloading rate was $2.25: 1$ to a certain stress state before sandstone specimen failure by the force control method, and the lateral unloading rate was $0.5 \mathrm{MPa} / \mathrm{min}$.

(3) Second unloading stage: according to the predetermined experimental scheme, the application of axial load and the unloading of lateral load continued until the sandstone specimen was damaged. Acoustic emission tests were carried out in three stages simultaneously. Part of the experimental process diagram was shown in Figure 9.

\section{Results and Discussion}

4.1. Characteristics of Full Stress-Strain Curves. The stressstrain curve can reflect important mechanical deformation characteristics of the rock. Figure 10 shows the test results of sandstone samples with various initial confining pressures and different protective layer mining modes. It can be seen that the axial stress-strain curves of different protective layer mining modes have almost same change trend. The whole process can be divided into five stages: hole crack compaction stage, elastic deformation stage, yield stage, stress drop stage, and residual strength stage. With the initial confining pressure being increasing, the stress drop phenomenon is not obvious. It can be due to the promoting effect of initial confining pressure on inhibiting failure of the specimen.

It has been demonstrated that $\mathrm{AE}$ ringing number reflects damage evolution process of the rock, and its variation law is in good agreement with stress-strain curves. In the hole crack compaction stage, $\mathrm{AE}$ cumulative ringing count increases steadily, which is caused by acoustic emission signals generated 
TABLE 2: Experimental plan table.

\begin{tabular}{|c|c|c|c|c|c|c|}
\hline \multirow[t]{2}{*}{ Serial number } & \multirow[t]{2}{*}{$\begin{array}{l}\text { Initial confining } \\
\text { pressure }(\mathrm{MPa})\end{array}$} & \multirow[t]{2}{*}{ Mode of mining } & \multirow[t]{2}{*}{$\Delta \sigma_{1} / \Delta \sigma_{3}$} & \multirow[t]{2}{*}{$\begin{array}{l}\text { Axial loading } \\
\text { rate }\left(\mathrm{MPa} \cdot \mathrm{min}^{-1}\right)\end{array}$} & \multicolumn{2}{|c|}{$\begin{array}{c}\text { Confining } \\
\text { pressure } \\
\text { unloading rate } \\
\left(\mathrm{MPa} \cdot \mathrm{min}^{-1}\right)\end{array}$} \\
\hline & & & & & $\sigma_{2}$ & $\sigma_{3}$ \\
\hline 1 & \multirow{2}{*}{15} & Soft rock protective layer & 9.13 & 4.565 & 0.5 & 0.5 \\
\hline 2 & & Coal seam protective layer & 7.65 & 3.825 & 0.5 & 0.5 \\
\hline 3 & 20 & Soft rock protective layer & 6.84 & 3.42 & 0.5 & 0.5 \\
\hline 4 & \multirow{2}{*}{25} & Soft rock protective layer & 5.47 & 2.735 & 0.5 & 0.5 \\
\hline 5 & & Coal seam protective layer & 4.59 & 2.295 & 0.5 & 0.5 \\
\hline
\end{tabular}

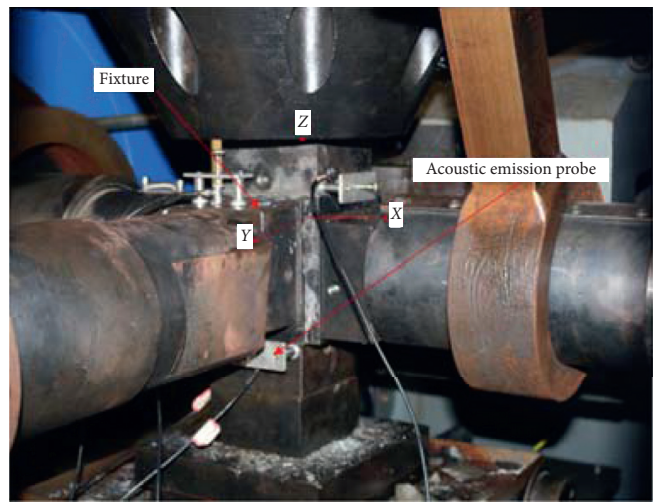

(a)

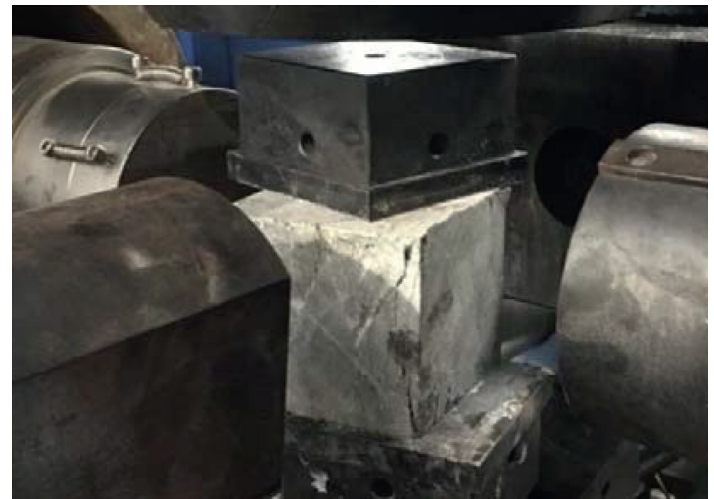

(b)

Figure 9: Experimental process diagram.

by the compressive closure of primary pores and fissure in sandstone samples. In the elastic deformation stage, the ringcount is still less, and the cumulative ring-count increases slowly. When the load increases to yield stage, the acoustic emission signal is gradually enhanced. There are more acoustic emission pulse cluster signals in this phase, indicating that the internal cracks in rock samples continue to occur, expand, and coalesce. When the stress goes to be strength limit of the sample, the cumulative ringing count increases rapidly and reaches the maximum value. Then, the cracks of sample and acoustic emission signal decrease. Meanwhile, the curves between axial stress and axial strain of different protective layer mining modes show a large deformation platform near the peak strength, which is caused by unloading effect of the confining pressure.

\subsection{Mechanical and Deformation Characteristics of Sandstone} under Different Protective Layer Mining Modes. Because of the same unloading rate of confining pressure, the axial loading rate of different mining modes is different. Taking the initial confining pressure of $15 \mathrm{MPa}$ as an example, the mining-induced mechanics characteristics of rock samples were analyzed for different protective layer mining modes. When the rock sample was loaded to the hydrostatic pressure stage, three directions were all in the compression state. Therefore, the starting points of loading and unloading were taken as the initial state for analysis. Figure 11 shows the characteristic curves of mining-induced mechanics behaviors under different protective layer mining modes.
It is found that the volume strain of different protective layer mining modes not only presents the volume compression relative to initial state in the initial unloading stage, but also shows the volume expansion in the final unloading stage (failure stage). The pressure-relief effect of protective layer can cause the volume expansion of coal-rock mass, which reveals the pressure-relief antireflection mechanism of protective layer mining. Figure 12 shows the specific mechanical differences of different protective layer mining modes.

In Figure 12(a), both peak strength and strain of rock samples increase with the increase of velocity ratio on axial loading. The peak strength and strain of soft rock protective layer mining are $92.53 \mathrm{MPa}$ and $2.24 \%$, which are $6.49 \mathrm{MPa}$ and $0.16 \%$ higher than those of coal seam protective layer mining. They increase by $7.5 \%$ and $7.69 \%$, respectively. The reason is that the increase rate of the axial stress $\left(\sigma_{1}\right)$ on rock sample is greater than the decrease rate of the confining pressure, and the effective stress acting on the sample is greater, and the strength of sample can be improved. In Figures 12(b) and 12(c), the larger the loading/unloading velocity ratio, the larger the transverse ( $X$ direction) strain, and the larger the confining pressure. When the specimen is damaged, the transverse load (confining pressure) of soft rock protective layer mining is $8.15 \mathrm{MPa}$, while that of coal seam protective layer is $6.17 \mathrm{MPa}$. The confining pressure is not unloaded to 0 , and the specimen is unstable and damaged. It indicates that the axial pressure is still dominant failure in the whole process of instability. 

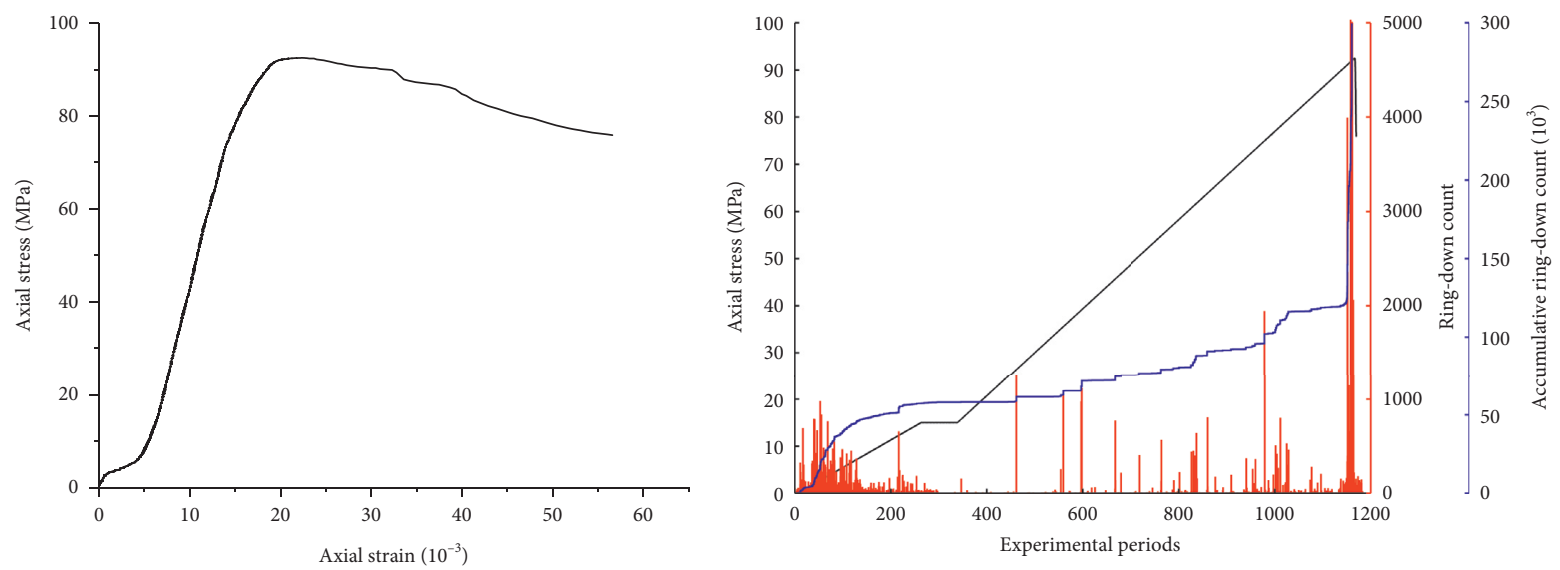

- Axial stress

Ring-down count

—_ Accumulative ring-down count

(a)
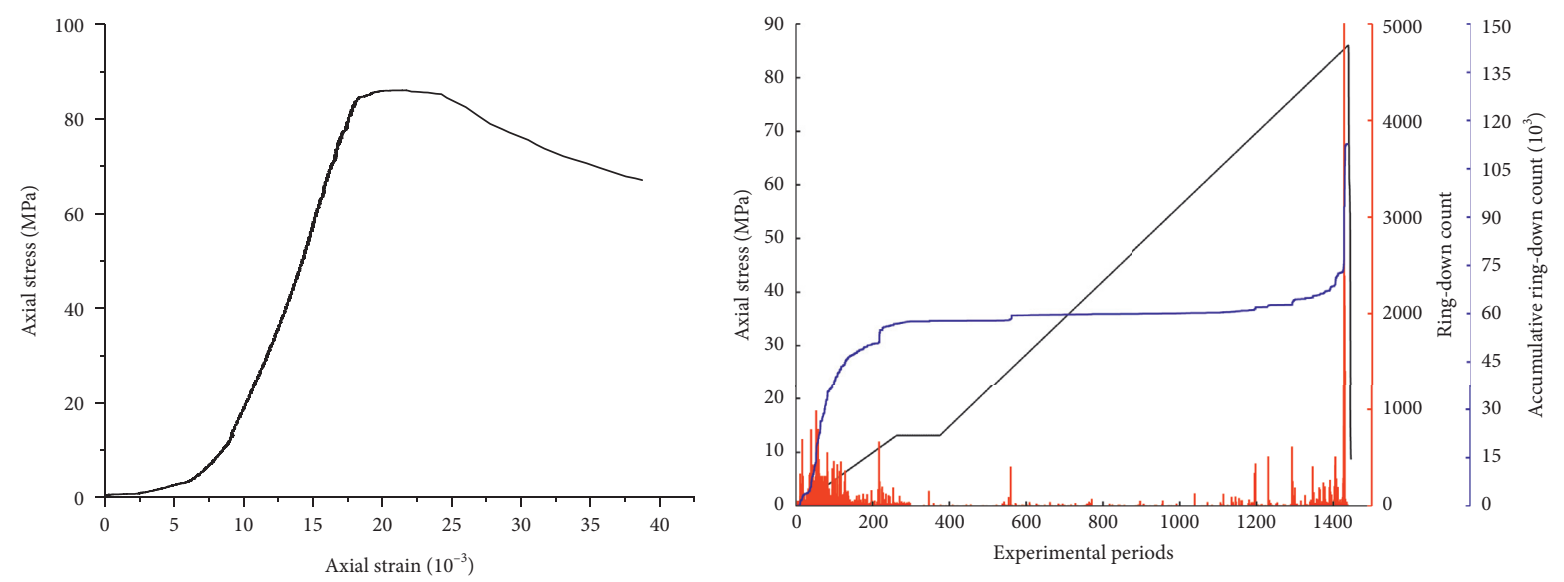

- Axial stress

Ring-down count

Accumulative ring-down count

(b)
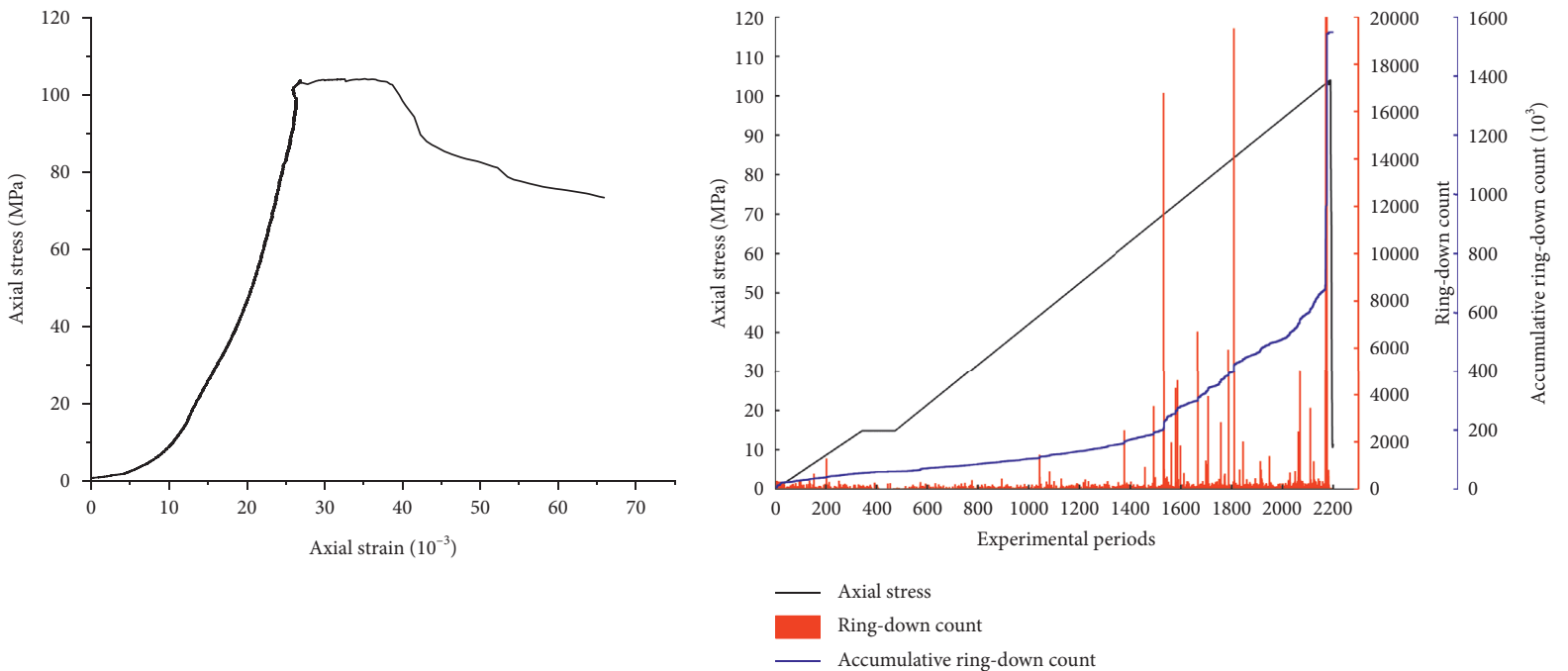

(c)

Figure 10: Continued. 

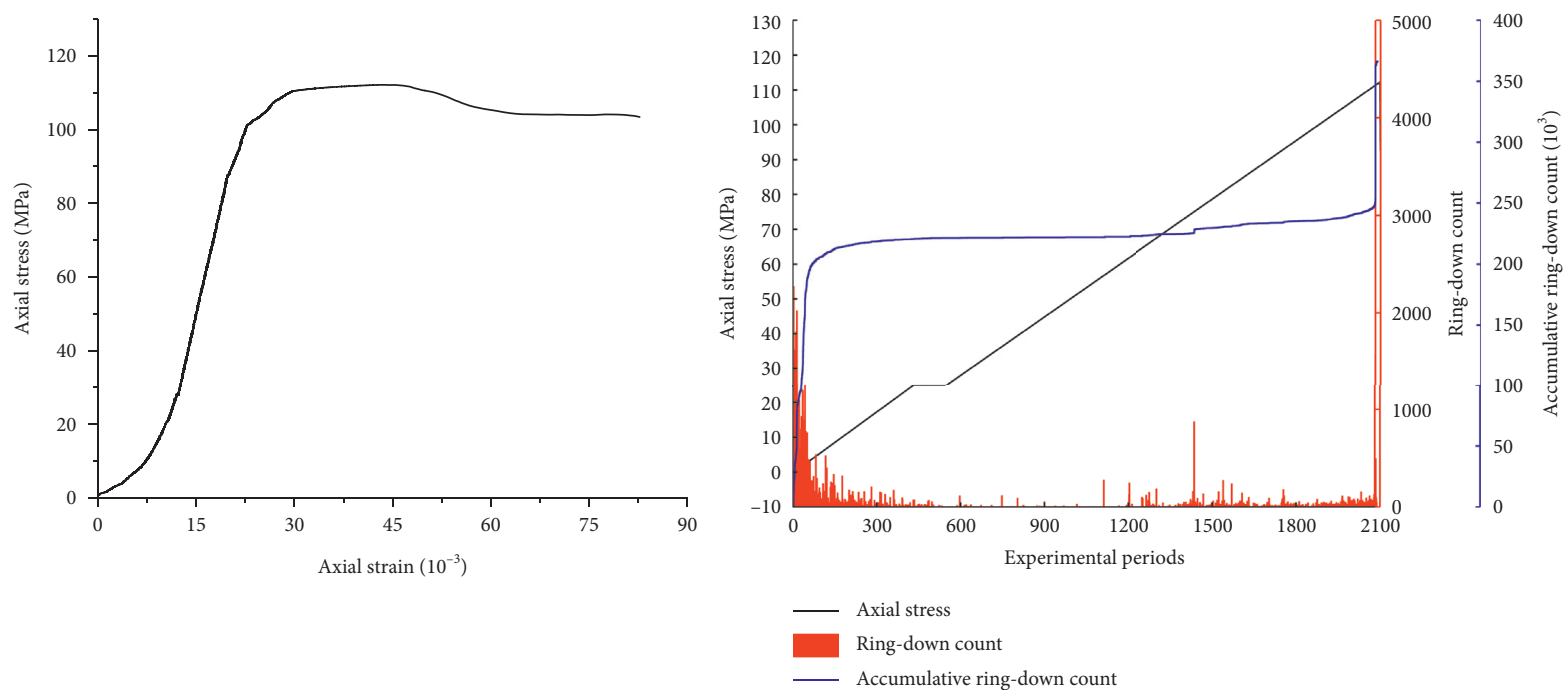

(d)
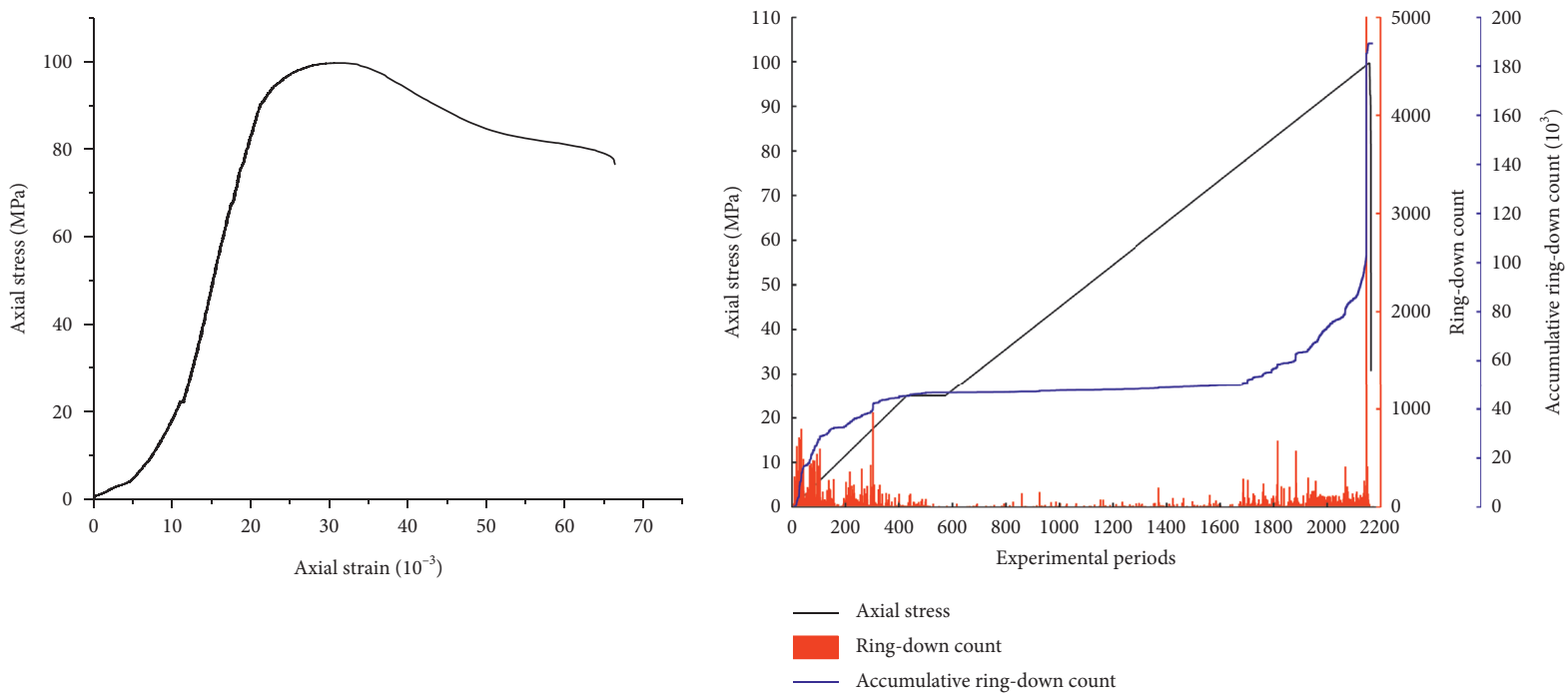

(e)

Figure 10: Stress-strain curves under different protective layer mining modes. (a) Initial confining pressure of $15 \mathrm{MPa}$ for soft rock protective layer mining. (b) Initial confining pressure of $15 \mathrm{MPa}$ for coal seam protective layer mining. (c) Initial confining pressure of $20 \mathrm{MPa}$ for soft rock protective layer mining. (d) Initial confining pressure of $25 \mathrm{MPa}$ for soft rock protective layer mining. (e) Initial confining pressure of $25 \mathrm{MPa}$ for coal seam protective layer mining.

The calculation formula of volumetric strain is as follows:

$$
\varepsilon_{v}=\varepsilon_{X}+\varepsilon_{Y}+\varepsilon_{Z}
$$

where $\varepsilon_{Z}$ is the axial strain; $\varepsilon_{X}$ is the strain along $X$ direction; $\varepsilon_{Y}$ is the strain along $Y$ direction. In Figure 12(d), after the loading and unloading begins, the sandstone starts to deform. The transverse strain (in $X$ and $Y$ directions) turns into swelling deformation due to the reduction of transverse load. Before the sample is destroyed, the axial strain is greater than transverse strain, and the volume shrinkage occurs. When the sandstone is damaged, the transverse strain increases rapidly, and volumetric strain begins to develop in the opposite direction, transforming from compression state to dilatation. With the increase of the axial loading rate ratio, the volumetric strain decreases when the sample is destroyed. The volumetric strain is $0.3 \%$ for the soft rock protective layer mining, while that of coal seam protective layer mining is $4.7 \%$. The results show that the smaller the ratio of loading/unloading velocity, the larger the volume expansion when the coal-rock mass reaches peak stress, and the more developed the gas flow channel, which is more conducive to pressure-relief and flow of gas.

\subsection{Strength Characteristics of Sandstone with Different} Confining Pressures for Soft Rock Protective Layer Mining. The rock samples are loaded by mining-induced mechanics loads under different confining pressures for the soft rock protective layer mining. The mining-induced mechanics of coal-rock mass are correlated with the confining pressure. 


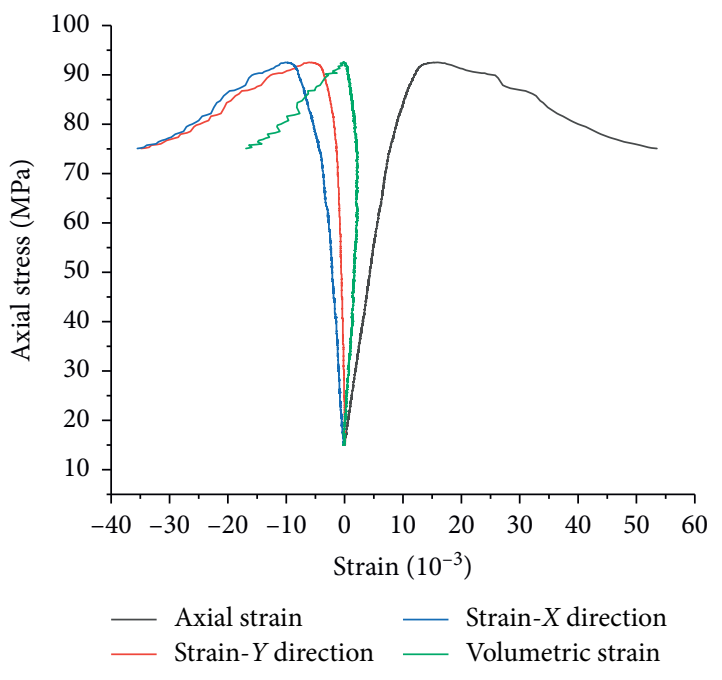

(a)

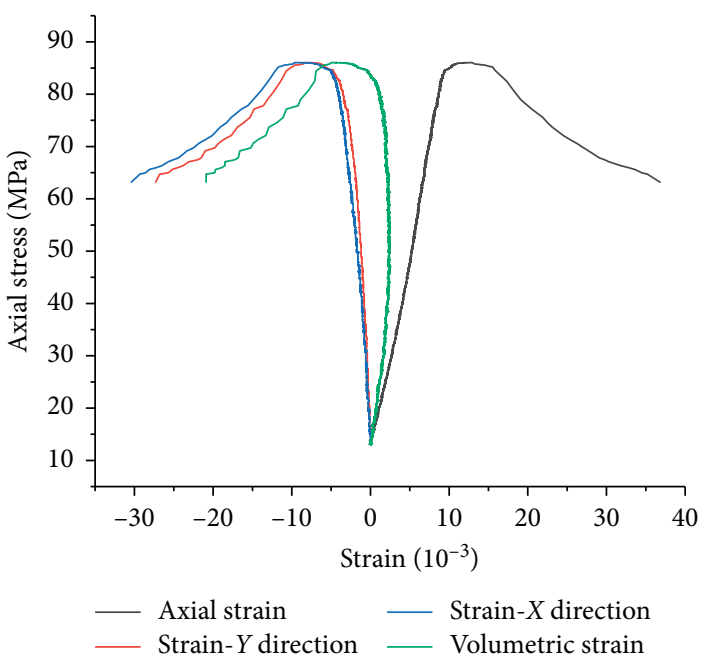

(b)

FIGURE 11: Mining-induced mechanical characteristic curves of different protective layer mining modes. (a) Soft rock. (b) Coal seam.

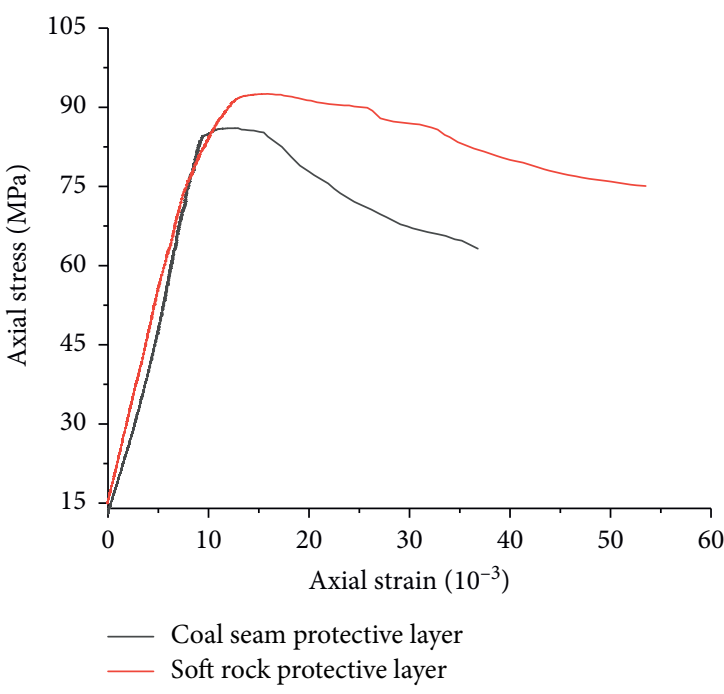

(a)

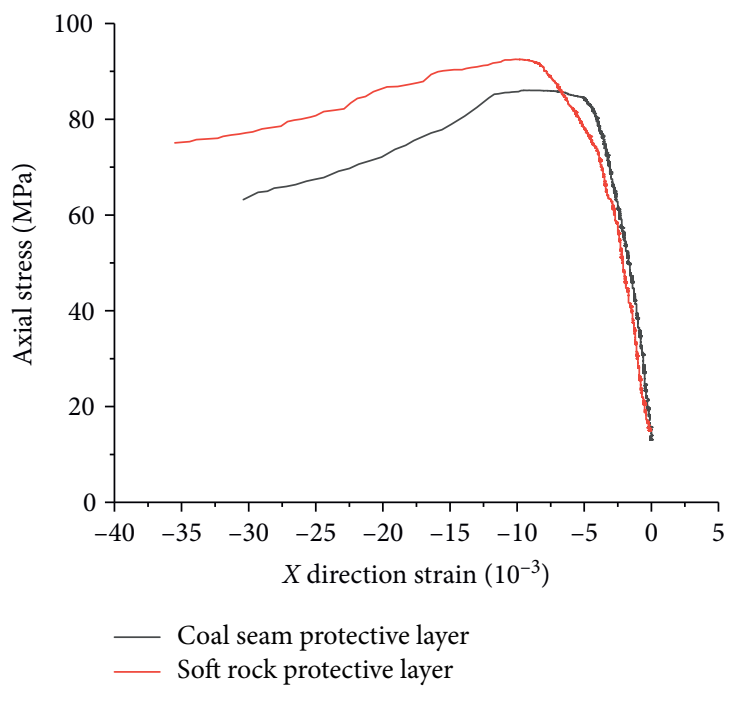

(c)

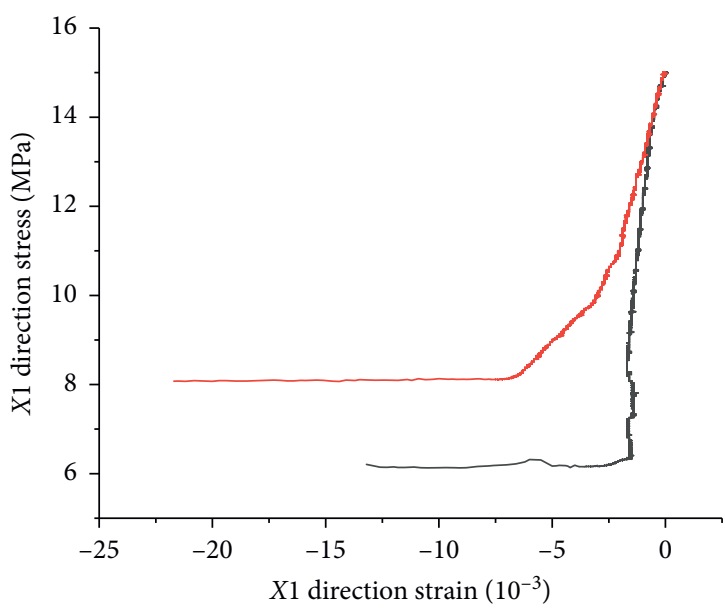

Coal seam protective layer

Soft rock protective layer

(b)

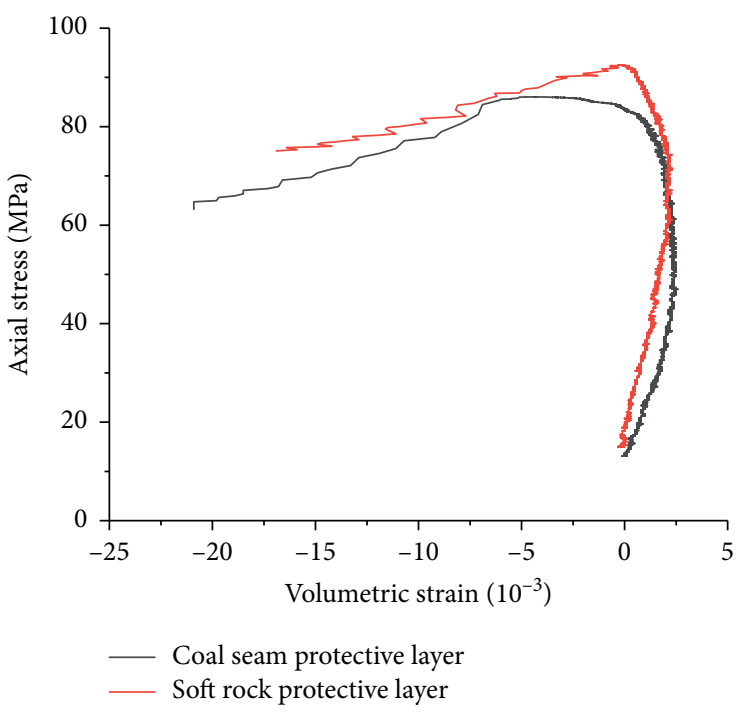

(d)

Figure 12: Comparison of mechanical differences under different protective layer mining modes. (a) Axial strain. (b) X1 direction strain. (c) $X$ direction strain. (d) Volumetric strain. 
Figure 13 shows the relation curve between peak strength, peak strain, and confining pressure reduction of sandstone with different confining pressures in soft rock protective layer mining. With the increase of initial confining pressure, the axial strain gradually increases when the stress of rock samples reaches its maximum strength, and the confining pressure reduction also increases. The axial stress, axial strain, and confining pressure reduction corresponding to rock sample at failure can all be expressed linearly by confining pressure. The correlation coefficients of the corresponding fitting expression are all above 0.96 . The formula is as follows:

$$
F\left(\sigma_{1}, \varepsilon_{1}, \Delta P\right)=k P+b
$$

where $k, b$, and correlation coefficients are obtained by $\sigma_{1}, \varepsilon_{1}$ and $\Delta P$, respectively, fitted with the confining pressure $P$, as listed in Table 3.

\section{Engineering Applications}

Luling Coal Mine in Huaibei belongs to a dangerous mine with high gas-outburst. There are three coal seams of No. 8, No. 9, and No. 10 (referred to as seams 8, 9, and 10) in III1 mining area of new working level, which has a prominent gas-outburst risk. For seam 8, the thickness is $6.28-13.25 \mathrm{~m}$, consistent coefficient is 0.26 on average, the permeability coefficient is $0.0277 \mathrm{~m}^{2}$ / $\mathrm{MPa}^{2} \cdot \mathrm{d}$, and permeability is $0.0007 \mathrm{mD}$. It is a typical thick, soft, and low-permeability coal seam. The average distance of seam 9 is $2.0 \mathrm{~m}$, and the distance from seam 8 is about $3 \mathrm{~m}$. Seam 10 can be divided into two layers, namely, No. 10-1 and No. 10-2 coal seams. The average distance from seam 8 and seam 9 is $83 \mathrm{~m}$. The geological structure of III1 mining area is complex, and 28 faults are found. Most of faults are NNE compression-torsional reverse faults with high angle. The sample came from seam 8 as the main mining seam, and its pore characteristics were analyzed by scanning electron microscopy test and Mercury injection test. Figure 14 shows the scanning electron microscope (SEM) images of the samples. We can see that the coal matrix inside raw samples possesses an uneven and rough surface. Moreover, the coal matrix contains a large number of original damages such as micro-/meso-cracks, which are characterized by scales decorated with some fine particles. Moreover, many micropores and micro-cracks are relatively developed on the coal samples.

Figure 15 shows the statistical analysis results of Mercury injection data from seam 8 . The micropores and small pores in seam 8 account for $55.72 \%$ and $29.76 \%$ of the total pore volume, while the proportion of mesopores and macropores is only $14.61 \%$. It indicates that seam 8 has high development of micropores and small pores, while mesopores and macropores have low development. Gas in the coal seam has a large adsorption space, and the diffusion and migration of the channel are less, leading to the high risk of gas outburst. After the mensuration, the gas parameters of various main coal seams in III1 mining area are listed in Table 4. The findings indicate that III1 mining area is facing extremely serious problems of gas control.

In order to liberate seam 8 and seam 9, seam 10 , reserved for the protective seam mining, is a traditional protective mining mode due to its relatively small threat of gas outbursts. Nevertheless, it has been reported that when seam 10 in III1 mining area is used as the initial mining pressure-relief layer, it is hard to choose mining process [26]. Thus, it is difficult to control gas and guarantee mining safety. Seam 10 cannot meet mining conditions of the protective layer, so the traditional protective layer mining is faced with great challenges. It is urgent to reselect the mining position of protective layer within the range of coal seam groups.

The study shows that the volume expansion of coalrock mass can be caused by pressure-relief effect of protective layer mining for coal seam and soft rock. It reveals the pressure-relief antireflection mechanism of protective layer mining by the experimental, which lays a theoretical foundation for the selection mining of soft rock protective layer. After deep mining, the smaller the loading/unloading velocity ratio with the increase of depth, the larger the volume expansion at peak stress. It shows that the soft rock protective layer mining in deep can play a good effect of pressure-relief protection. When the traditional coal seam protective layer is not suitable for mining, and it is difficult to achieve regional gasoutburst prevention effect without mining the protective layer. Under such a technical background, it is necessary to create design concept and put forward a new gascontrol technology of soft rock protective layer for low permeability and high-gas coal seams (groups) in deep.

The core exploration is conducted in the range of $20 \mathrm{~m}$ above roof of seam 10 to $30 \mathrm{~m}$ down floor of seam 9 in III 1 mining area, as shown in Figure 16. Two relatively stable rock seams were found. One lied 43-48 m below the floor of seam 9 and developed an average thickness of 1-5 m and an average hardness of 7 . The rock seam consisted of medium sandstone. The other lied 54-64 m (average $59 \mathrm{~m}$ ) below the floor of seam 9 and developed an average thickness of $5.1 \mathrm{~m}$, and its average hardness was 3.73, which belonged to grey mudstone with Kaolin clay. The rock seam of medium sandstone and grey mudstone with Kaolin clay can be used as the first mining rock protective layer. Comprehensive analysis of rock protective layer working face mining technology, mining conditions, and other factors such as mudstone is selected as the target layer for mining after the analysis to solve the problem of gas control in the protected layer, as shown in Figure 17. 


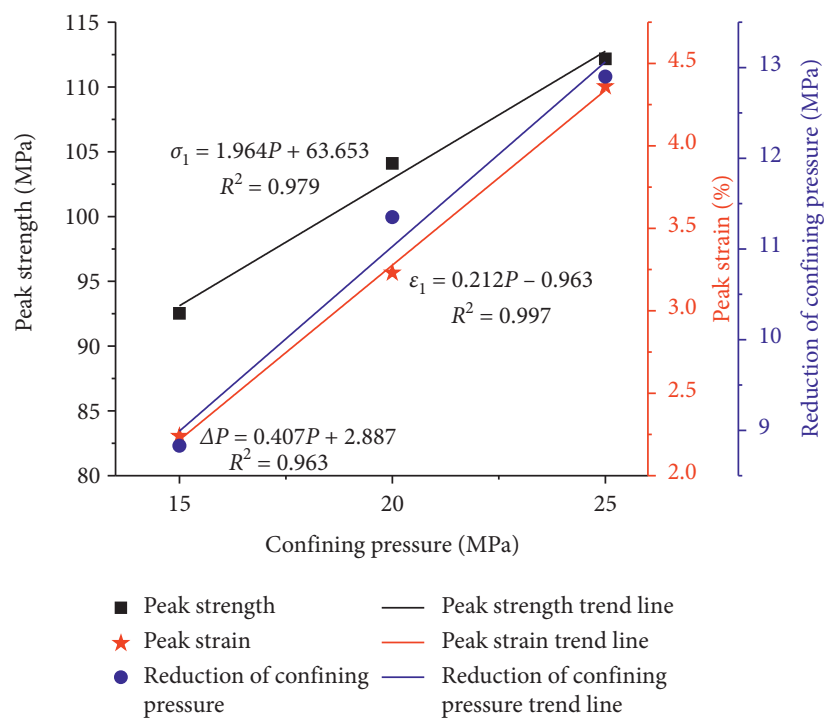

FIGURE 13: Relationship between confining pressure and peak strength, peak strain, and reduction of confining pressure under soft rock protective layer mining.

TABLE 3: $k, b$, and correlation coefficients.

\begin{tabular}{lccc}
\hline Parameter & $k$ & $b$ & $R$ \\
\hline Peak strength $\left(\sigma_{1}\right)$ & 1.964 & 63.653 & 0.979 \\
Peak strain $\left(\varepsilon_{1}\right)$ & 0.212 & -0.963 & 0.997 \\
Reduced value of confining pressure $(\Delta P)$ & 0.407 & 2.887 & 0.963 \\
\hline
\end{tabular}
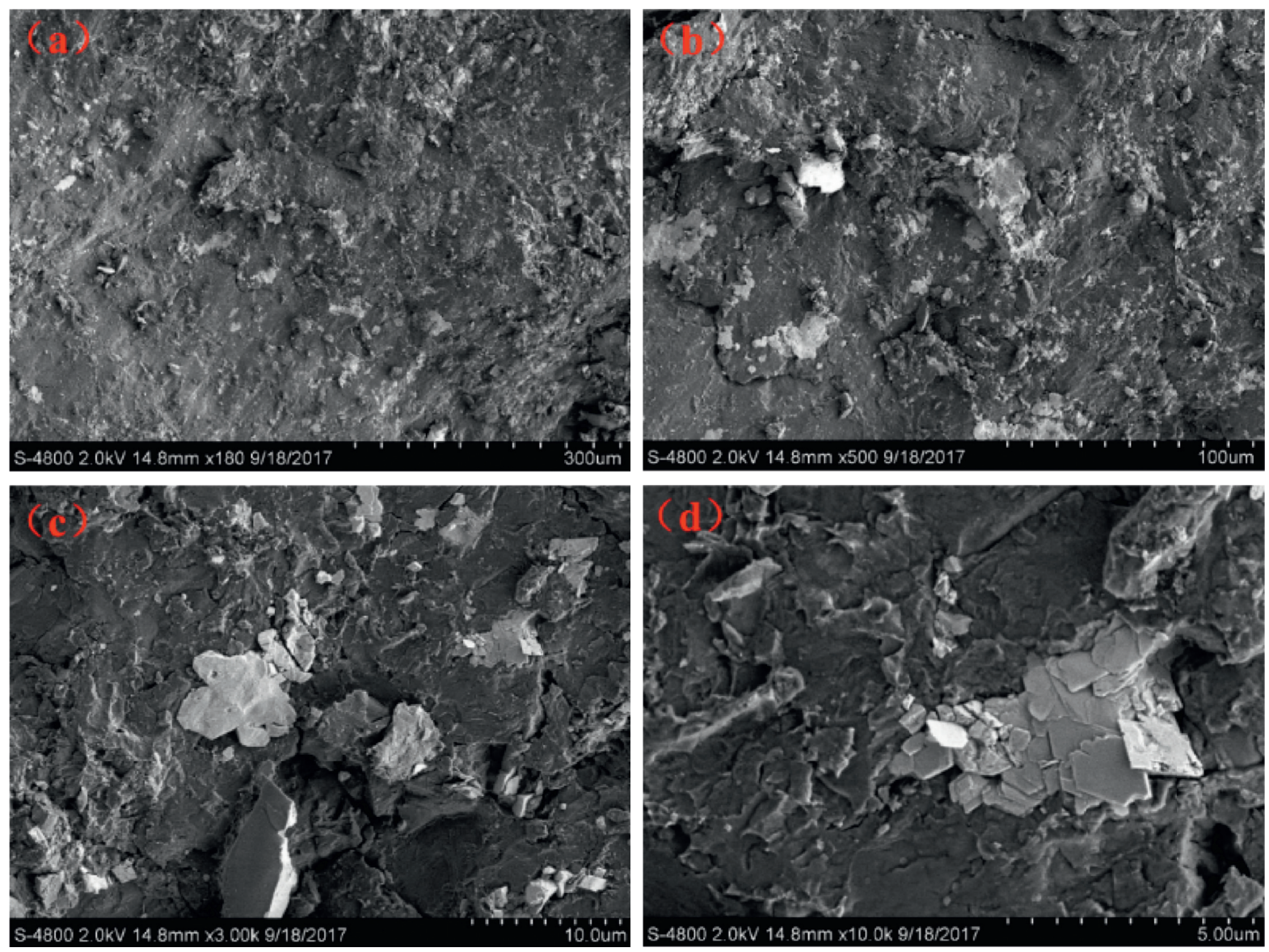

FIgURE 14: (a-d) SEM images with different magnifications of the coal sample. 


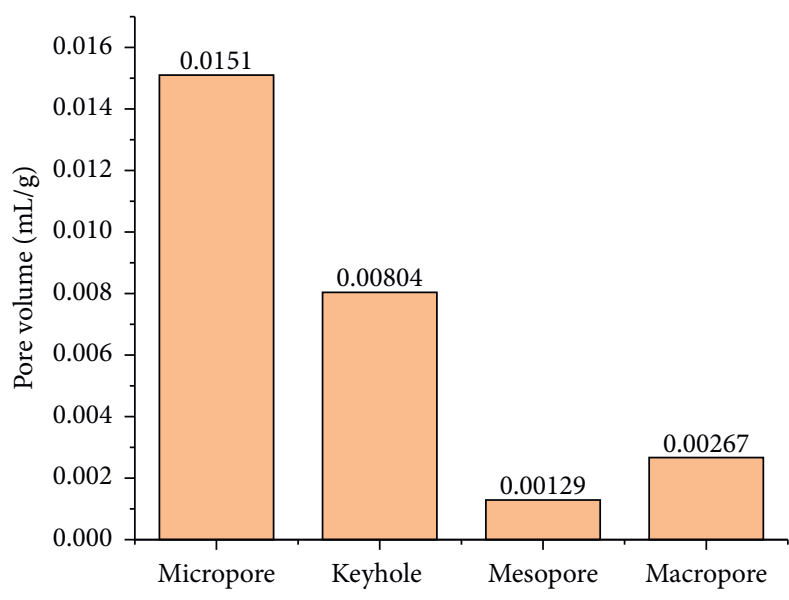

(a)

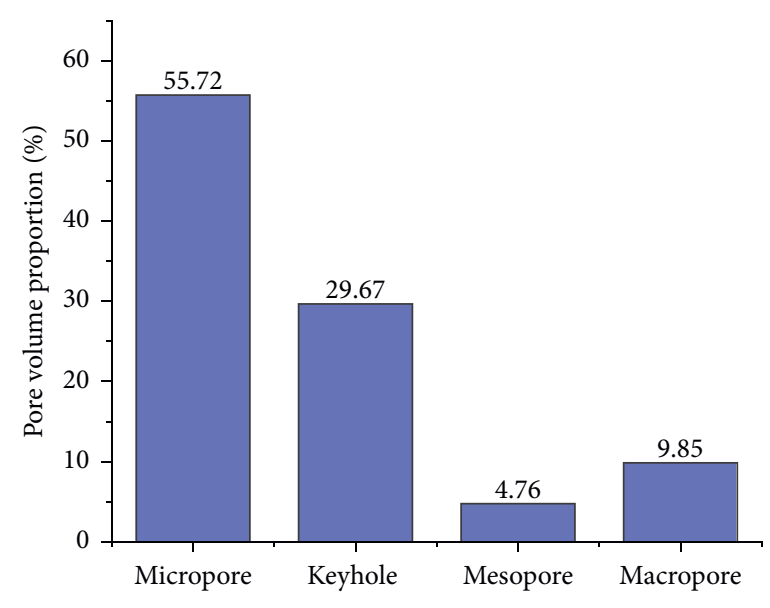

(b)

Figure 15: Pore volume distribution and proportion of no. 8 coal seam in Luling mine. (a) Pore volume. (b) Pore volume proportion.

TABle 4: Gas parameters of no. 8, no. 9, and no. 10 coal seams in III1 mining area.

\begin{tabular}{|c|c|c|c|c|c|c|c|}
\hline \multirow{2}{*}{ Seam } & \multirow{2}{*}{$\begin{array}{l}\text { Gas pressure } \\
(\mathrm{MPa})\end{array}$} & \multirow{2}{*}{$\begin{array}{l}\text { Gas content } \\
\left(\mathrm{m}^{3} / \mathrm{t}\right)\end{array}$} & \multicolumn{2}{|c|}{ Adsorption constant } & \multirow{2}{*}{$\begin{array}{c}\text { Coal } \\
\text { hardness }\end{array}$} & \multirow{2}{*}{$\begin{array}{c}\text { Porosity } \\
(\%)\end{array}$} & \multirow{2}{*}{$\begin{array}{l}\text { Initial velocity of initial gas } \\
\text { diffusion }(\mathrm{mL} / \mathrm{s})\end{array}$} \\
\hline & & & $a\left(\mathrm{~m}^{3} / \mathrm{t}\right)$ & $b\left(\mathrm{MPa}^{-1}\right)$ & & & \\
\hline Nos. 8 and 9 & $4.43-6.47$ & $22.67-25.63$ & $35.59-39.06$ & $0.48-0.53$ & $0.1-0.3$ & 4.61 & $17-30$ \\
\hline No. 10 & $2.7-5.3$ & 13 & $15.25-29.83$ & $0.41-1.3$ & $0.8-1.13$ & 6.87 & $7.6-8.9$ \\
\hline
\end{tabular}

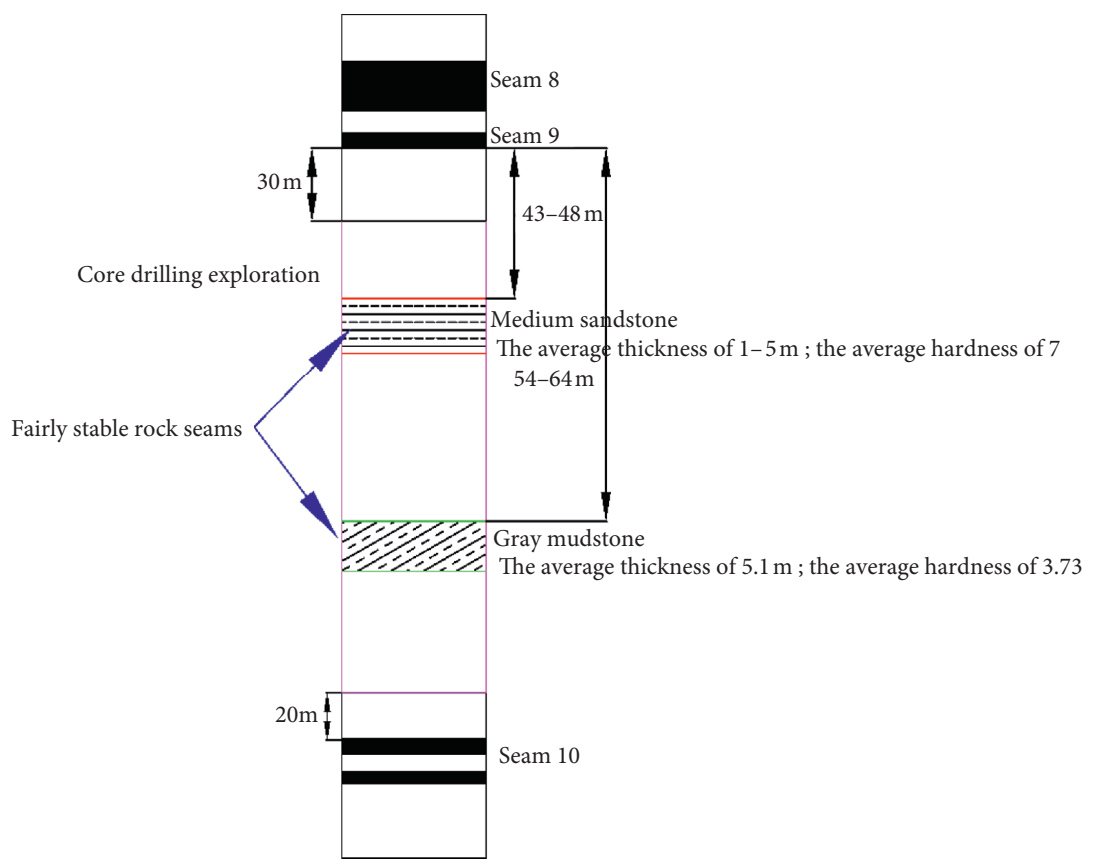

Figure 16: Determination of the horizon of rock mining. 


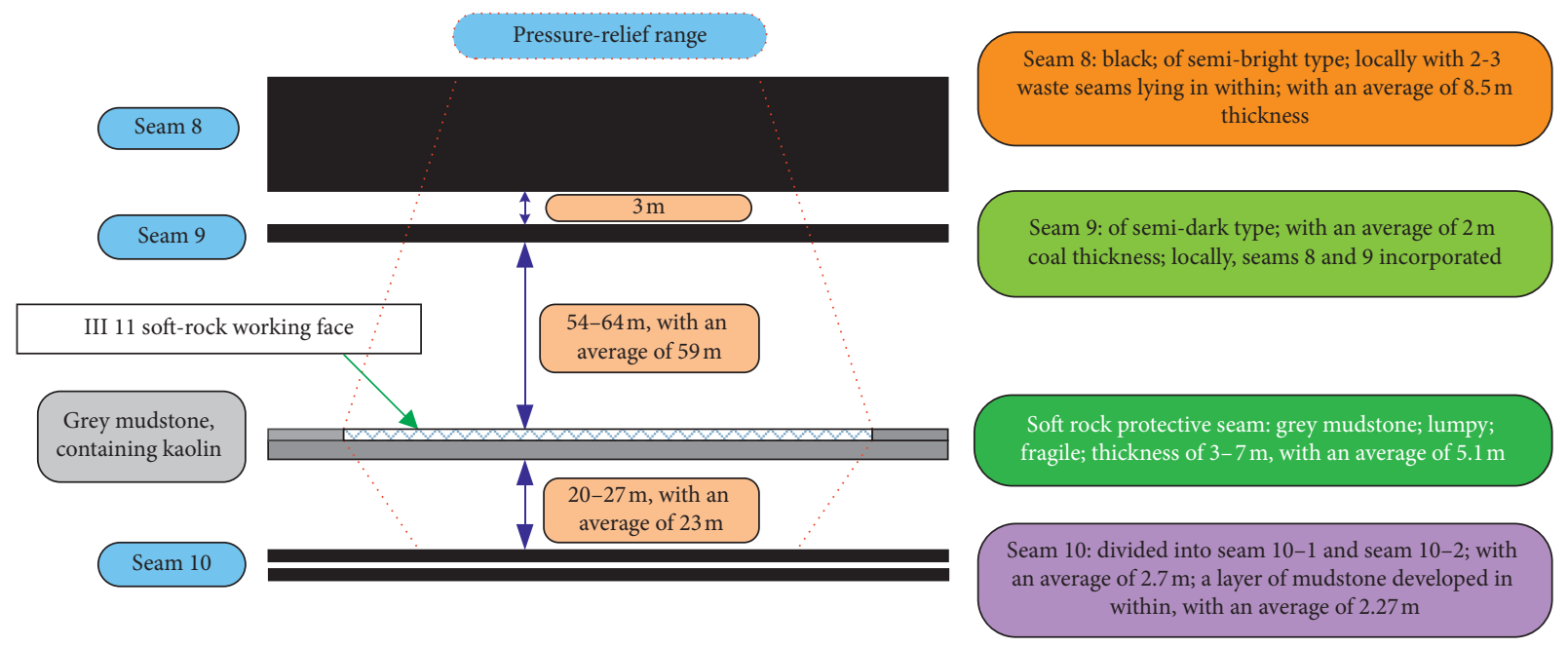

FIGURE 17: Selection diagram of soft-rock protective seam in III1 mining area.

\section{Conclusions}

(1) By exploring the effect of stratum lithology on stress environment in front of stope, it was found that the peak value of abutment pressure increased with the increase of stratum lithology strength. The reason was that the ability of the "coal (or rock) wall-fallen rock gangue" supporting system to support the overburden formation structure is different after mining working face. The results showed that stress concentration coefficients of soft rock and coal seam mining modes were 1.9 and 1.7 , respectively, under the simulated geological conditions. Moreover, the stress path of different protective layer mining modes was determined. In the secondary unloading stage, the ratio of axial stress increase and confining pressure unloading in the soft rock protective layer mining was $2: 1$, and that of coal seam protective layer mining was $1.5: 1$.

(2) The axial stress-strain curves of different protective layer mining modes had the same variation trend, which could be divided into the pore fissure compaction stage, elastic deformation stage, yield stage, stress drop stage, and residual strength stage. The volume strain of different protective layer mining modes showed volume expansion at the end of unloading (failure stage), which revealed the pressure-relief antireflection mechanism of the protective layer mining. Under the same confining pressure, the peak stress and peak strain increased with the increase of loading/unloading velocity ratio. Meanwhile, the reduced value of confining pressure increased at failure, while the volume expansion decreased.

(3) Gas control was faced with severe problems for III1 mining area in Luling Coal Mine, and the traditional coal seam protective layer mining encountered great challenge. The research results were applied to the selection mining of soft rock protective layer in III1 mining area, which innovated the mining way of protective layer. Furthermore, it proposed a new gascontrol technology of working face in soft rock protective layer for deep coal seams (groups) with low permeability and high gas.

\section{Data Availability}

The data used to support the findings of this study are available from the corresponding author upon request.

\section{Conflicts of Interest}

The authors declare that they have no conflicts of interest.

\section{Acknowledgments}

This work was financially supported by National Natural Science Foundation of China (Nos. 52004005, 51974009, 51874002, and 52004008), China Postdoctoral Science Foundation (No. 2021M691185), Anhui Provincial Natural Science Foundation (Nos. 2008085QE222 and 2008085QE260), Anhui Provincial Key Research and Development Plan (No. 201904a07020010), Anhui University of Science and Technology Introduction of Talents Research Fund Project, Scholastic Key Project (No. QN2019113), Patent Transformation and Cultivation Project (No. ZL201907), and Independent Research Fund of the State Key Laboratory of Mining Response and Disaster Prevention and Control in Deep Coal Mines (No. SKLMRDPC19ZZ012).

\section{References}

[1] E. Zha, S. Y. Wu, Z. T. Zhang et al., "Mining-induced mechanical response of coal and rock at different depths: a case study in the pingdingshan mining area," Arabian Journal of Geosciences, vol. 13, no. 19, Article ID 972, 2020.

[2] L. Wang, Z. Lu, D. P. Chen et al., "Safe strategy for coal and gas outburst prevention in deep-and-thick coal seams using a 
soft rock protective layer mining," Safety Science, vol. 129, Article ID 104800, 2020.

[3] Z. Zhang, R. Zhang, H. Xie, M. Gao, and J. Xie, "Mininginduced coal permeability change under different mining layouts," Rock Mechanics and Rock Engineering, vol. 49, no. 9, pp. 3753-3768, 2016.

[4] M. Q. Yang, H. P. Xie, M. Z. Gao et al., "On distribution characteristics of the temperature field and gas seepage law of coal in deep mining," Thermal Science, vol. 24, no. 6B, pp. 3923-3931, 2020.

[5] R. Gao, B. Yu, and X. Meng, "Stress distribution and surrounding rock control of mining near to the overlying coal pillar in the working face," International Journal of Mining Science and Technology, vol. 29, no. 6, pp. 881-887, 2019.

[6] Z. l. Li, L. M. Dou, W. Cai, G. F. Wang, Y. L. Ding, and Y. Kong, "Roadway stagger layout for effective control of gobside rock bursts in the longwall mining of a thick coal seam," Rock Mechanics and Rock Engineering, vol. 49, no. 2, pp. 621-629, 2016.

[7] W. Yang, B.-Q. Lin, Q. Yan, and C. Zhai, "Stress redistribution of longwall mining stope and gas control of multi-layer coal seams," International Journal of Rock Mechanics and Mining Sciences, vol. 72, pp. 8-15, 2014.

[8] H. Wang, Y. Jiang, Y. Zhao, J. Zhu, and S. Liu, "Numerical investigation of the dynamic mechanical state of a coal pillar during longwall mining panel extraction," Rock Mechanics and Rock Engineering, vol. 46, no. 5, pp. 1211-1221, 2013.

[9] H. P. Xie, H. W. Zhou, J. F. Liu et al., "Mining induce mechanical behavior in coal seams under different minging layouts," Journal of China Coal Society, vol. 36, no. 7, pp. 1067-1074, 2011.

[10] R. Zhang, T. Ai, H. Li, Z. Zhang, and J. Liu, "3D reconstruction method and connectivity rules of fracture networks generated under different mining layouts," International Journal of Mining Science and Technology, vol. 23, no. 6, pp. 863-871, 2013.

[11] J. P. Zuo, L. F. Liu, H. Zhou, and Y. Huang, "Deformation failure mechanism and analysis of rock under different mining condition," Journal of China Coal Society, vol. 38, no. 3, pp. 1319-1324, 2013.

[12] Z. H. Wang, J. C. Wang, S. L. Yang, L. H. Li, and M. Li, "Failure behaviour and acoustic emission characteristics of different rocks under uniaxial compression," Journal of Geophysics and Engineering, vol. 17, no. 1, pp. 76-88, 2020.

[13] H. Y. Wang, G. D. Wang, G. J. Zhang, F. Du, and J. Ma, "Acoustic emission response characteristics of anthracitic coal under uniaxial compression," Shock and Vibration, vol. 2020, Article ID 8874164, 12 pages, 2020.

[14] H. Yin, C. Yang, H. Ma et al., "Study on damage and repair mechanical characteristics of rock salt under uniaxial compression," Rock Mechanics and Rock Engineering, vol. 52, no. 3, pp. 659-671, 2019.

[15] R. Peng, Y. Ju, J. G. Wang, H. Xie, F. Gao, and L. Mao, “Energy dissipation and release during coal failure under conventional triaxial compression," Rock Mechanics and Rock Engineering, vol. 48, no. 2, pp. 509-526, 2015.

[16] Z. Jia, H. Xie, R. Zhang et al., "Acoustic emission characteristics and damage evolution of coal at different depths under triaxial compression," Rock Mechanics and Rock Engineering, vol. 53, no. 5, pp. 2063-2076, 2020.

[17] G. Zhang, W. Zhang, H. Wang et al., "Microscopic failure mechanism analysis of sandstone under triaxial compression," Geotechnical \& Geological Engineering, vol. 37, no. 2, pp. 683-690, 2019.
[18] R. Yang, X. D. Wang, H. Zha et al., "Classification and fractal characteristics of limestone fragments obtained in conventional compression and cyclic loading tests under uniaxial and triaxial conditions," Advances in Materials Science and Engineering, vol. 2020, Article ID 3802471, 16 pages, 2020.

[19] Z. L. Li, L. G. Wang, Y. L. Lu, W. S. Li, and K. Wang, "Experimental investigation on the deformation, strength, and acoustic emission characteristics of sandstone under true triaxial compression," Advances in Materials Science and Engineering, vol. 2018, Article ID 5241386, 16 pages, 2018.

[20] Y. Xue, P. G. Ranjith, F. Gao et al., "Mechanical behaviour and permeability evolution of gas-containing coal from unloading confining pressure tests," Journal of Natural Gas Science and Engineering, vol. 40, pp. 336-346, 2017.

[21] J. Li, F. Lin, H. Liu, and Z. Zhang, "Triaxial experimental study on changes in the mechanical properties of rocks under different rates of confining pressures unloading," Soil Mechanics and Foundation Engineering, vol. 56, no. 4, pp. 246252, 2019.

[22] H. G. Zhao, C. Liu, and G. Huang, "Dilatancy behaviour and permeability evolution of sandstone subjected to initial confining pressures and unloading rates," Royal Society Open Science, vol. 8, no. 1, Article ID 201792, 2021.

[23] Q. Minggao and S. Pingwu, Mine Pressure and Strata Control, China University of Mining and Technology Press, Xuzhou: China, 2003.

[24] X. Cheng, G. M. Zhao, Y. M. Li, X. R. Meng, C. L. Dong, and Z. H. Liu, "Researches of fracture evolution induced by soft rock protective seam mining and an omni-directional stereo pressure-relief gas extraction technical system: a case study," Arabian Journal of Geosciences, vol. 11, Article ID 326, 2018.

[25] H. Xie, X. Zhao, J. Liu, R. Zhang, and D. Xue, "Influence of different mining layouts on the mechanical properties of coal," International Journal of Mining Science and Technology, vol. 22, no. 6, pp. 749-755, 2012.

[26] X. Cheng, G. Zhao, Y. Li, X. Meng, and Q. Tu, "Key technologies and engineering practices for soft-rock protective seam mining," International Journal of Mining Science and Technology, vol. 30, no. 6, pp. 889-899, 2020. 